\title{
DNA Fragmentation Factor Subunit Beta
}

National Cancer Institute

\section{Source}

National Cancer Institute. DNA Fragmentation Factor Subunit Beta. NCI Thesaurus. Code C126527.

DNA fragmentation factor subunit beta (338 aa, $\sim 39 \mathrm{kDa}$ ) is encoded by the human DFFB gene. This protein is involved in the modulation of DNA fragmentation and chromosome condensation during apoptosis. 